\title{
ROLE OF DRYING ON INTERACTION BETWEEN SULFATES AND IRON (HYDR)OXIDES SURFACES
}

\author{
ROMAIN BOTELLA*, LEFEVRE GREGORY ${ }^{1}$
}

${ }^{1}$ PSL Research University, CNRS, Institut de Recherche de

Chimie Paris, Chimie ParisTech, 75005 Paris, France,

*correspondence: romain.botella@chimieparistech.psl.eu

Drying is a common phenomenon, from the soil surface hydration/dehydration cycle to the catalyst supports impregnation, as well as in sol-gel synthesis. Environment is most likely impacted by the drying of sorbed molecules or ions on soils [1], and this is therefore important to address this subject. In this work, we develop a new methodology to follow the evolution of the speciation of adsorbates after drying, using sulfate ions sorbed on iron (hydr)oxides as a reference system.

When going from a solution/solid interface to a gas/solid interface, the volume of solution first shrinks, then forms a thin film, before disappearing. The structure of such a thin film of water has been studied on silica [2, 3] using in situ infrared (IR) spectroscopy but the effect of drying on the adsorbate speciation has been seldom studied. Speciation of adsorbed sulfate on iron (hydr)oxides is well known [4, 5] and spectra recorded after after drying have shown a modification of the adsorbate geometry [4, 6]. However, systematic study of the evolution of the surface complexes during drying has never been done so far.

In this work, we aim at studying the behavior of adsorbed sulfate anions on iron (hydr)oxides such as goethite after isothermally drying the interface. To do so, we are using ATR-FTIR spectroscopy a tool of choice in the study of solid/solution interfaces [6,7]. After adsorption of sulfate ions, the changes of the adsorbate while drying (gaseous nitrogen flow) is studied In Situ by changing the $\mathrm{pH}$ of adsorption in the system $[2,3]$.

Bibliography: [1] Kaiser, Kleber \& Berhe (2015) Soil Biol. Biochem. 80, 324-340. [2] Asay \& Kim( 2005) J. Phys. Chem. B 109, 16760-16763. [3] Peixinho, Lefèvre, Coudert \& Hurisse (2013) Colloid Interface Sci. 408, 206-211. [4] Kitadai, Nishiuchi \& Tanaka (2018) Geochim. Cosmochim. Acta 238, 150-168. [5] Hug (1997) J. Colloid Interface Sci. 188, 415-422. [6] Peak, Ford \& Sparks (1999) J. Colloid Interface Sci. 218, 289-299. [7] McQuillan (2001) Adv. Mater. 13, 1034-1038. 